\title{
Maintenance of quality of life improvement for patients with chronic pain and obesity after interdisciplinary multimodal pain rehabilitation - A study using the Swedish Quality Registry for Pain Rehabilitation
}

Huan-Ji Dong, Britt Larsson, Marcelo Rivano Fischer and Björn Gerdle

The self-archived postprint version of this journal article is available at Linköping University Institutional Repository (DiVA):

http://urn.kb.se/resolve?urn=urn:nbn:se:liu:diva-161832

N.B.: When citing this work, cite the original publication.

Dong, H., Larsson, B., Fischer, M. R., Gerdle, B., (2019), Maintenance of quality of life improvement for patients with chronic pain and obesity after interdisciplinary multimodal pain rehabilitation - A study using the Swedish Quality Registry for Pain Rehabilitation, European Journal of Pain, 23(10), 1839-1849. https://doi.org/10.1002/ejp.1457

Original publication available at:

https://doi.org/10.1002/ejp.1457

Copyright: Wiley (12 months)

http://eu.wiley.com/WileyCDA/ 


\title{
Maintenance of quality of life improvement for patients with chronic pain and obesity after interdisciplinary multimodal pain rehabilitation - a study using the Swedish Quality Registry for Pain Rehabilitation (SQRP)
}

\author{
H-J. Dong ${ }^{1}$, B. Larsson ${ }^{1}$, M. Rivano Fischer ${ }^{2,3}$, B. Gerdle ${ }^{1}$ \\ ${ }^{1}$ Pain and Rehabilitation Centre, and Department of Medical and Health Sciences, Linköping University, \\ Linköping, Sweden \\ ${ }^{2}$ Lund University, Department of Health Sciences, Rehabilitation Medicine, Lund, Sweden, ${ }^{3}$ Skane \\ University Hospital, Department of Neurosurgery and Pain Rehabilitation, Lund, Sweden
}

Running title: Quality of life improvement for patients with chronic pain and obesity

Correspondence:

Huan-Ji Dong

Pain and Rehabilitation Centre,

University Hospital

SE 58185 Linköping

Sweden

Phone +46730488933

Fax: +46101034906

E-mail: huanji.dong@liu.se

Submission category: original article

Research funding: This study was supported by grants from the County Council of Östergötland (Research-ALF) and AFA insurance. AFA Insurance, a commercial founder, is owned by Sweden's labour market parties: The Confederation of Swedish Enterprise, the Swedish Trade Union Confederation (LO), and The Council for Negotiation and Cooperation (PTK). These parties insure employees in the private sector, municipalities, and county councils. AFA Insurance does not seek to generate a profit, so no dividends are paid to shareholders. The sponsors of the study had no role in study design, data collection, data 
analysis, data interpretation, writing of the report, or the decision to submit for publication. The authors had full access to all the data in the study and had final responsibility for the decision to submit for publication.

Conflicts of interest: none.

Significance: Patients with chronic pain and comorbid obesity achieve sustained improvements in Health-Related Quality of Life (HRQoL) from Interdisciplinary Multimodal Pain Rehabilitation (IMMPR). This finding suggests that rehabilitation professionals should consider using IMMPR for patients with comorbid obesity even though their improvement may not reach the same level as for non-obese patients. 


\section{Abstract}

Background: Throughout the world many people have both obesity and chronic pain, comorbidities that decrease Health-Related Quality of Life (HRQoL). It is uncertain whether patients with comorbid obesity can maintain improved HRQoL after Interdisciplinary Multimodal Pain Rehabilitation (IMMPR).

Methods: Data from 2016, 2017, and 2018 were obtained from a national pain database for Swedish specialized pain clinics and collected at three time points: Pre-IMMPR; PostIMMPR; and 12-month follow-up (FU-IMMPR). Participants (N=872) reported body weight, height, pain aspects, and HRQoL (RAND 36-Item Health Survey). Severe obesity (Body Mass Index, BMI $\geq 35 \mathrm{~kg} / \mathrm{m}^{2}$ ) was defined according to WHO classifications. We used linear mixed regression models to examine BMI group differences in HRQoL over time.

Results: More than $25 \%$ of patients (224/872) were obese and nearly $30 \%(63 / 224)$ of these were severely obese. All BMI groups improved significantly in both physical and mental composites of HRQoL after IMMPR (Pre- vs. Post-IMMPR, $\mathrm{P}<0.001$ ). The improvements were maintained at a 12-month follow-up (Post- vs. FU-IMMPR, P $>0.05$ ). The severe obesity group had the lowest physical health score and least improvement (pre- vs. FU-IMMPR, Cohen's $d=0.422$, small effect size). Severe obesity had negative impact on physical health $(\beta=-4.39, \mathrm{P}<0.05)$ after controlling for sociodemographic factors and pain aspects.

Conclusion: Improvements in HRQoL after IMMPR were achieved and maintained across all weights, including patients with comorbid obesity. Only severe obesity was negatively associated with physical health aspects of HRQoL.

Significance: Patients with chronic pain and comorbid obesity achieve sustained HealthRelated Quality of Life (HRQoL) improvements from Interdisciplinary Multimodal Pain Rehabilitation (IMMPR). This finding suggests that rehabilitation professionals should consider using IMMPR for patients with comorbid obesity even though their improvement may not reach the same level as for non-obese patients. 


\section{Introduction}

Obesity and chronic pain are common comorbidities that often lead to hardships (Cooper, Ells, Ryan, \& Martin, 2018; Hitt, McMillen, Thornton-Neaves, Koch, \& Cosby, 2007; Marcus, 2004; Narouze \& Souzdalnitski, 2015; Okifuji \& Hare, 2015; Stone \& Broderick, 2012). More than $50 \%$ of the European population is overweight or obese (Marques, Peralta, Naia, Loureiro, \& de Matos, 2018), resulting in substantial economic burdens for patients and society (Phillips, 2009; Tremmel, Gerdtham, Nilsson, \& Saha, 2017), and 20\% of Europeans report chronic pain of at least moderate intensity(Breivik, Collett, Ventafridda, Cohen, \& Gallacher, 2006).

Although the causal obesity-pain relationship has not been fully explored, evidence suggests that obesity and pain adversely affect one another as they share underlying mechanical, physiological, psychological, and behavioural mechanisms (McVinnie, 2013; Okifuji \& Hare, 2015; Zdziarski, Wasser, \& Vincent, 2015).

Quantitative and qualitative research have tried to identify barriers to treating the two comorbidities. For example, Arranz et al. describe the relationship between obesity and pain as a vicious circle that challenges rehabilitation efforts: pain-inactivity-obesity-pain (Arranz, Rafecas, \& Alegre, 2014). In another qualitative study, Cooper et al. found that 'overweight/obesity contributed to fear and catastrophizing, which resulted in avoidance of exercise that would have assisted their weight loss' (Cooper, Ells, et al., 2018). As these insights suggest, providing pain rehabilitation to patients across all the weight classes and expecting similar results will be challenging.

According to the VAPAIN initiative, Health-Related Quality of Life (HRQoL) is one of the main outcome domains in Interdisciplinary Multimodal Pain Rehabilitation (IMMPR) (Kaiser et al., 2018). Prior studies have linked HRQoL both with obesity and pain (Arranz et al., 2014; Barofsky, Fontaine, \& Cheskin, 1997; Heo, Allison, Faith, Zhu, \& Fontaine, 2003). This association is not a direct linear correlation, but a result of accumulated effects when obesity and pain coexist. In other words, individuals with the two comorbidities may have worse HRQoL compared to patients with only one of the two conditions. Given that these two comorbidities affect HRQoL simultaneously, we asked whether focus only on pain management is sufficient for improving HRQoL in obese patients.

As the comorbidity of obesity and pain is prevalent (Hitt et al., 2007; Narouze \& Souzdalnitski, 2015), pain rehabilitation considers weight status. There is some indication that patients benefit from IMMPR irrespective of weight status across BMI classes (Castel et 
al., 2015; Koball, Craner, \& Sperry, 2016). However, Koball et al.'s study (Koball et al., 2016) did not investigate the sustainable improvements at follow-up and Castel et al.'s study (Castel et al., 2015) included only female fibromyalgia patients. Therefore, this study aims to investigate chronic pain patients in real-world practice settings registered in the SQRP with respect to the following research questions:

Is obesity overrepresented in patients referred to specialist pain clinics in Sweden?

In comparison to normal weight patients, do patients with obesity report more severe pain?

Is obesity an obstacle factor for chronic pain patients to improve HRQoL and maintain improvements after IMMPR?

Which factors influence HRQoL maintenance over time? 


\section{Methods}

The Swedish Quality Registry for Pain Rehabilitation (SQRP)

Recognized by the Swedish Association of Local Authorities and Regions, the Swedish

Quality Registry for Pain Rehabilitation (SQRP) receives data from pain clinics at the specialist level throughout Sweden. In 2010, The Boston Consulting Group ranked SQRP as one of the top ten high-quality national registries in Sweden ("Boston Consulting Group," 2010). SQRP uses questionnaires to capture patients' sociodemographic background, pain characteristics, psychological symptoms, function, activity/participation aspects, and HRQoL. Previous publications provide a more detailed description of these variables (Gerdle, Molander, Stenberg, Stalnacke, \& Enthoven, 2016). In 2016, two variables - self-reported body weight and height - were added to the SQRP. Patients complete the SQRP questionnaires on up to three occasions: during the first physician visit (Pre-IMMPR or baseline); immediately after IMMPR (Post-IMMPR); and at a 12-month follow-up after IMMPR (FU-IMMPR). In this study, we extracted data from two consecutive years, between 2016 and 2018, so as to cover IMMPR participants from pre-IMMPR through FU-IMMPR.

\section{Participants}

For this study, patients were asked to participate in the SQRP after being referred to a specialized pain clinic due to complex chronic non-malignant pain conditions. A bio-psychosocial assessment revealed that these patients presented psychological symptoms and other comorbidities, reported large difficulties with their pain, and their condition severely affected their working life and participation in social activities. In addition, they often did not respond to routine pharmacological/physiotherapeutic treatments delivered in a monodisciplinary fashion. Exclusion criteria were substance abuse and ongoing major somatic or psychiatric disease. The participants $(\mathrm{N}=872)$ were $\geq 18$ year, registered in the SQRP, completed selected measurements (described below), treated with the IMMPR, and completed the SQRP at all three occasions (Pre-IMMPR, Post-IMMPR, and FU-IMMPR).

The study was conducted in accordance with the Helsinki Declaration and Good Clinical Practice and approved by the Ethical Review Board in Linköping (Dnr: 2015/108-31). All participants received written information about SQRP research and gave their written consent.

\section{Measurements}

Sociodemographic characteristics

Data collected included age, sex, educational level, place of birth, and working status. Educational level was classified as follows: elementary school, upper secondary school or 
vocational training, and college or university. Place of birth was categorised as Sweden, another Nordic country, Europe except Nordic country, or country outside Europe. Before IMMPR and at the follow-up, participants were asked about their occupation: working status (employed or self-employed), studies, or neither. This variable was dichotomised into working/studying and not working/studying.

\section{Pain aspects}

Pain intensity (NRS-7d) was defined as average pain intensity during the previous week using a numeric rating scale $0-10$ with numbers for guidance $0=$ no pain and $10=$ worst possible pain). Minimal clinically important difference (Cook, 2008) for pain is considered as a change of pain intensity of at least 30\% (Farrar, Young, LaMoreaux, Werth, \& Poole, 2001).

Pain duration was determined by asking a single question: When did you first experience the pain you are currently troubled by (days)?

Pain-duration-persistent was determined by asking a single question: If persistent pain exists, how long (days)?

Pain distribution (Pain Region Index, PRI) was determined using 36 predefined anatomical areas (18 on the front and 18 on the back of the body). The participants marked where they experienced pain: 1) head(face, 2) neck, 3) shoulder, 4) upper arm, 5) elbow, 6) forearm, 7) hand, 8) anterior aspect of chest, 9) lateral aspect of chest, 10) belly, 11) sexual organs, 12) upper back, 13) low back, 14) hip/gluteal area, 15) thigh, 16) knee, 17) shank, and 18) foot. The number of areas with pain were summed (i.e., between 0 and 36) and this created a Pain Region Index (PRI) for the participants.

\section{Anthropometric variables}

Information on height and weight were self-reported or measured and registered during the clinical assessment. BMI $\left(\mathrm{kg} / \mathrm{m}^{2}\right)$ was calculated as weight $(\mathrm{kg}) /$ height $(\mathrm{m})^{2}$ and classified according to the World Health Organization (WHO) criteria: $<18.5=$ underweight; 18.5-24.9 $=$ normal range; $25.0-29.9=$ overweight; $30.0-34.9=$ obesity; and $\geq 35.0=$ severe obesity.

The validity of measured weight- and height-calculated BMI and BMI derived from selfreported values have previously been investigated. High correlations were reported between the two measures (Pearson's $r=0.89-0.97$ for different age groups and gender) (Kuczmarski, Kuczmarski, \& Najjar, 2001). Based on the measured BMI, self-reported values (sensitivity 
of $88.1 \%$ and specificity of $97.4 \%$ ) are used to identify overweight/obesity (Vuksanović et al., 2014).

Psychological symptoms

A self-assessment questionnaire was used to measure anxiety and depression - Hospital Anxiety and Depression Scale (HADS) (Zigmond \& Snaith, 1983). HADS is devided into an anxiety subscale (HAD-A) and a depression subscale (HAD-D). Both subscales have seven items, scoring range between 0 and 21, where a lower score indicates a lower possibility of anxiety or depression. HADS is frequently used in clinical practice as well as in research and has good psychometric characteristics (Bjelland, Dahl, Haug, \& Neckelmann, 2002; Zigmond \& Snaith, 1983). HADS has the following clinical cut-offs: 0-7 = no symptoms; 8-10= probably symptomatic; and $\geq 11=$ severely symptomatic (Zigmond \& Snaith, 1983). A cut-off value of $\geq 11$ for severe symptomatology was used to define the minimal clinically important difference after IMMPR. HADS has been validated in its Swedish translation (Lisspers, Nygren, \& Soderman, 1997).

HRQOL

RAND-36 is one of the generic profile HRQoL measures used to compare the relative burden of chronic disease (Hays \& Morales, 2001; Hays, Sherbourne, \& Mazel, 1993). Comprising 36 items, RAND-36 assesses eight health dimensions with multi-item scales, including physical functioning (10 items), role limitations caused by physical health problems (4 items), role limitations caused by emotional problems (3 items), social functioning ( 2 items), emotional wellbeing (5 items), energy/fatigue (4 items), pain ( 2 items), and general health perceptions (5 items). In addition, one item assesses change in perceived health during the previous 12 months. In each health dimension, every term is transformed linearly to a 0-100 possible range (per cent of total possible score) and then total score averages are calculated in the same scale. This calculation yields eight scale scores (ranging 0-100). Two summary scores, physical and mental health composites (PCS and MCS), were also derived from these eight scales. We used the two summaries in this study.

Statistical analysis

All statistics were performed using the statistical package IBM SPSS Statistics (version 23.0). Data are presented as means with standard deviation (SD) for variables with normal distribution and medians with interquartile range (IQR) for variables with non-Gaussian distribution. SQRP uses predetermined rules to handle single missing items of a scale or a subscale; details about this procedure are reported elsewhere (Gerdle et al., 2016). To 
investigate differences among the groups with different BMI categories, we used Chi-square, one-way ANOVA (Bonferroni method for post hoc test), and Kruskal-Wallis Test (MannWhitney $U$ test with Bonferroni method for post hoc test). A p-value of below 0.05 was regarded as statistically significant. A P-value $<0.017$ was used for Mann-Whitney U test, which served as a post hoc test to control for the risk of mass significance (Altman, 1991). To investigate within group changes at the one-year follow-up, we used paired sample t-test and calculated effect size (ES, Cohen's $d=t / \sqrt{ } N)$ (Lakens, 2013) to quantify the differences between Pre-IMMPR and FU-IMMPR. The effect size (Cohen's d) was considered large if $\geq 0.80$, moderate if $0.50-0.79$, small if $0.20-0.49$, and insignificant if $<0.20$ (Cohen, 1988).

To avoid likewise deletion of missing data in repeated measures ANOVA, we structured linear mixed models to analyse repeated measures at three time points: Pre-IMMPR, PostIMMPR, and FU-IMMPR. The models can also deal with time-varying covariates. Two summary scores of HRQoL measured on the three IMMPR occasions, PCS and MCS, served as dependent variables. Time (Pre-, Post-, and FU-IMMPR) was a repeated measure and treated as a categorical variable. To investigate the possible effect modifications with time and BMI group (TIME x BMI group), this interaction term was specified in all the models. The change in BMI (as a time-varying variable) was calculated by subtracting the BMI at Pre-IMMPR from the BMI at FU-IMMPR. BMI directly after IMMPR (Post-IMMPR) was assumed as unchanged. In model 1, only BMI group, change in BMI, time, and its interaction with BMI group were tested. In model 2, sociodemographic characteristics (working/study status as a time-varying variable) were added. In model 3, pain aspects (pain intensity as a time-varying variable) and psychological symptoms (HADs as time-varying variables) were added. Collinearity was prior tested and two variables - pain duration and pain-durationpersistent - had a high correlation of 0.764 . Pain-duration-persistent was removed from the models due to more missing data than that in pain duration. A repeated covariance type with unstructured statement fitted best (according to Akaike's information criterion) to account for correlations on an individual level between the repeated measures at baseline and the other two IMMPR occasions. Analysis was conducted using maximum likelihood estimation since our sample is not small (Singer \& Willett, 2003). The regression coefficients ( $\beta$ ) and standard error (SE) were generated in the regression models. F-statistic were reported when appropriate. 


\section{Results}

Sociodemographic characteristics

Table 1 summarises the sociodemographic characteristics. Most chronic pain patients were middle aged (45.8 \pm 10.5 years old), women $(n=700,80 \%)$, Swedish or European $(n=778$, $89.5 \%)$, and without college or university education $(628 / 872,72 \%)$. The proportion of work/study status increased at follow-up (Pre-IMMPR vs. FU-IMMPR, 57\% to 73.9\%, $\mathrm{P}<0.001)$.

More than one-fourth $(224 / 872,25.6 \%)$ of the study population was categorised as obese. Nearly one-third of the obese patients $(63 / 224,28.1 \%)$ were severely obese. Mean BMI did not change over the time (Pre- vs. FU-IMMPR, $\mathrm{P}>0.05$ ). Due to the low representation of underweight participants $(12 / 872,1.4 \%)$, this category was not considered in the later analysis.

Table 1 to be here.

Pain aspects, psychological symptom, and HRQoL

Obese patients reported longer pain duration than normal-weighted patients with respect to days since chronic pain debut and persistent pain duration (Table 2). Obese patients also had more pain spreading based on PRI (17 vs. 13, P<0.001). Pain intensity (NRS-7d) differed most significantly among the BMI groups at FU-IMMPR. At FU-IMMPR, the mild obesity group (6.2 \pm 2.3$)$ and the severe obesity group (6.4 \pm 2.0$)$ reported higher pain intensity than the normal weight group $(5.4 \pm 2.3, \mathrm{P}<0.001)$. Although significant decreases of pain intensity were found in all groups (Pre- vs. FU-IMMPR, Cohen's d 0.328 0.453, small ES, all $\mathrm{p}<0.05$ ) except for the overweight group (Pre- vs. FU-IMMPR), the changes were not clinically important (i.e., a decrease of at least $30 \%$ ).

Reported psychological symptoms measured by HADS did not differ statistically between weight groups at any of the three IMMPR measurements (Table 2). Significantly lower scores in all the groups were reported at follow-up (Pre- vs. FU-IMMPR, Cohen's d 0.363 0.524, small to moderate $\mathrm{ES}$, all $\mathrm{P}<0.01$ ). A further analysis of HADS score below clinical cut-off showed that fewer patients were included in the category 'severely symptomatic' (Pre- vs. FU-IMMPR, $\mathrm{P}<0.001$, data not shown), indicating that improvement was of clinical importance.

Table 2 to be here. 
All BMI groups showed significant improvements in the two composites of HRQoL (PCS and MCS) after IMMPR (Pre- vs Post-IMMPR, all $\mathrm{P}<0.001$, Figures 1 and 2). The improvements were stable and maintained at the follow-up (Pre- vs. FU- IMMPR, Cohen's d $0.328 \sim 0.579$, small to moderate ES, all $\mathrm{P}<0.05$; Post- vs. FU-IMMPR, all $\mathrm{P}>0.05$ ). The severe obesity group had the lowest PCS and the least improvement (Pre- vs FUIMMPR, Cohen's $d=0.422$, small ES, $\mathrm{P}<0.01$ ) (Figure 1). The other three groups with lower BMI had greater improvements (Cohen's $d>0.5$, moderate $\mathrm{ES}$, all $\mathrm{P}<0.001$ ). MCS did not show group differences at any of the three time points. The improvement in MCS after IMMPR was also rather limited in each group (mean difference 6.5 11.5, Cohen's $\mathrm{d}<0.5$, small ES). The group with severe obesity had the least improvement in MCS among the BMI groups (Pre- vs. FU-IMMPR, Cohen's d = 0.328, small ES, $\mathrm{P}<0.05$ ).

Figure 1 and figure 2 to be here.

Mixed linear regression of PCS and MCS

Coefficients of variables selected to determine the relationship with PCS or MCS changing over time (Pre-, Post-, and FU-IMMPR) are shown in Table 3. When only the BMI group was considered, time (Pre-, Post-, and FU-IMMPR), change in BMI, and time-BMI group interaction (BMI group $x$ time $)$ were part of the analysis. BMI group $(F(3,845)=6.559$, $\mathrm{P}<0.01)$ with mild obesity $(\beta=-5.59, \mathrm{P}<0.01)$ and severe obesity $(\beta=-10.34, \mathrm{P}<0.01)$ contributed negatively to PCS, but had no significant effect on MCS (model 1, Table 3). After adjusting for background factors, the significant impacts of BMI group on PCS remained (model 2, Table 3). For severe obesity, its significant negative effect also remained when pain aspects and psychological symptoms were added $(\beta=-4.39, \mathrm{P}<0.05$, model 3 in Table 3). For group difference over time, time-BMI group interaction did not show significant impact on PCS $(\mathrm{F}(6,799)=0.80, \mathrm{P}>0.05)$ or $\operatorname{MCS}(\mathrm{F}(6,770)=1.025, \mathrm{P}>0.05$, model 1 in Table 3); the insignificant effect remained in the other two models.

Among the sociodemographic factors in model 2 and model 3, work or study remained as a positive effect on both PCS $(\beta=1.8-3.36, \mathrm{P}<0.01)$ and $\operatorname{MCS}(\beta=1.6-5.7, \mathrm{P}<0.05)$. As expected, some variables also showed robust impacts on PCS and MCS (i.e., pain intensity and pain distribution, HADS-A (only upon MCS), and HADS-D).

Table 3 to be here. 


\section{Discussion}

The results of our study confirm that obesity is common among patients with chronic pain. In this study, over $25 \%$ of patients referred to Swedish specialist pain clinics were obese. This is a higher proportion than that reported in the overall Swedish population (approximately 15\%) (Sweden, 2018). In this study, obese patients reported longer duration of chronic pain, more widespread pain (PRI), and higher pain intensity, supporting the notion that obese chronic pain patients experience more severe pain than non-obese chronic pain patients. We found that IMMPR benefited patients across all the weight groups from normal weight through obesity with regard to improvements in HRQoL at discharge and at one-year follow-up. However, severely obese patients reported the least improvements in HRQoL after IMMPR, and severe obesity was negatively related to physical health over time. Finally, clinically important improvements after IMMPR were found for psychological symptoms, but not for pain intensity.

A further investigation on pain aspects showed that pain intensity, often considered to correlate with low HRQoL (Bernfort, Gerdle, Rahmqvist, Husberg, \& Levin, 2015; Breivik et al., 2006; Dysvik, Lindstrom, Eikeland, \& Natvig, 2004; Horng et al., 2005), only showed minor variations across the weight groups at Pre-IMMPR. Obese patients are known to experience lower HRQoL than other patients (Jia \& Lubetkin, 2005; Marcus, 2004; Simon et al., 2006), but our results indicate that before IMMPR patients were referred to specialist pain clinics they experienced similar levels of pain intensity regardless of weight group. Although obese patients had the least reduced pain intensity Post-IMMPR, no BMI group reported a reduction large enough to reach the minimal clinically important difference. Consistent with our findings, two other research groups focused on morbidly obese patients receiving weight loss interventions, also reported lack of clinically significant reduction in pain intensity (Cooper, Ryan, et al., 2018; Dunlevy et al., 2019). In the normal weight group, the effect size was small, but this must be seen in the perspective that these patients represent a selection of patients with complex chronic pain conditions. So far, we cannot blame excess weight as a major independent barrier in pain intensity reduction. Based on the present results, we cannot assume that changes in BMI per se will result in pain intensity reduction by IMMPR. As other studies have suggested, IMMPR's goal should not be the significant reduction of pain intensity (Bromley Milton et al., 2013; Gerdle et al., 2016; Turk et al., 2008; Turk \& Okifuji, 1999). 
Obese patients are known to experience more psychological symptoms than other patients (Jia \& Lubetkin, 2005; Marcus, 2004; Simon et al., 2006). In our study population, under the condition that patients are simultaneously suffering chronic pain, weight status seemed less significant in affecting psychological wellness. No statistically significant differences were found in HAD-A, HAD-D, or the mental aspect of HRQoL (as measured by MCS) between weight groups (Table 2 and Figure 2). Also, in the regression models, BMI could not explain the variation in MCS. Previous research, including our recent studies, have shown increased prevalence of psychological distress in complex chronic pain conditions and positive correlations between pain intensity and levels of psychological distress in these patients (Borsbo, Peolsson, \& Gerdle, 2009; Chopra \& Arora, 2014; Molander, Dong, Ang, Enthoven, \& Gerdle, 2018; Nicolson, Caplan, Williams, \& Stern, 2009). Hence, we may speculate that factors other than obesity status dominate or expand the negative influence on patients' mental wellness in complex chronic pain conditions.

Return to meaningful activity, such as work or study, can be a main objective for rehabilitation, since the majority of patients referred to IMMPR are of working age. From the regressions of both composites of HRQoL, it was evident that only work/study status was a significant regressor (Table 3). There are several reports, including longitudinal studies, that have found that more patients return to work and achieve better HRQoL after IMMPR (Chu et al., 2015; Hallstam, Lofgren, Svensen, \& Stalnacke, 2016; Rivano Fischer, Persson, Stalnacke, Schult, \& Lofgren, 2019; Westman et al., 2006). Our results clearly indicate that the two aspects of HRQoL investigated here had a positive influence on work/study status. Both pain aspects and psychological symptoms were important variables associated with patients' HRQoL according to the regression models (model 3 of PCS and MCS) (Table 3). Based on estimates of coefficients in the models, our results indicate that pain aspects had stronger effects on physical health HRQoL (measured by PCS), whereas psychological symptoms were more important for mental health HRQoL (measured by MCS). During IMMPR, PCS compared to MCS was more improved and the effect maintained over time when Pre-, Post-, and FU-IMMPR were considered. In rehabilitation, maintenance of improved outcomes is very important because it represents both long-term effects of pain rehabilitation and cost-effective treatment (i.e., reduced medical care) (Sletten, Kurklinsky, Chinburapa, \& Ghazi, 2015) and return to work (Norrefalk, Ekholm, Linder, Borg, \& Ekholm, 2008). 
The obesity epidemic continues in Sweden as well as around the world. In pain rehabilitation, weight status is receiving more attention (Koball et al., 2016; Marcus, 2004; Sellinger et al., 2010). There are concerns that the negative health consequences of obesity may restrict the pain rehabilitation process. However, our study supports studies that conclude that patients with different weight status benefit equally from IMMPR (Castel et al., 2015; Koball et al., 2016; Sellinger et al., 2010). The fact that we have used follow-up IMMPR data and found maintenance effects on HRQoL, clearly indicates that health professionals should offer IMMPR to patients regardless of weight status. However, our most complex model (model 3 in Table 3) of PCS indicates that severe obesity might be a barrier. To some extent, obesity seemed to negatively affect pain intensity (Table 2). On the other hand, having severe pain can be a barrier to weight loss for obese patients receiving weight management services (Masheb et al., 2015; Ryan et al., 2017). Both conditions, severe pain and extreme obesity, interfere with patients' attempts to improve in one or the other condition. The complex interwoven relationship suggested here reminds health professionals about the underlying mechanisms (McVinnie, 2013) and the necessity of targeting pain rehabilitation and weight management in an integrated fashion (Dunlevy et al., 2019; Janke et al., 2014).

This study has several limitations. First, we did not analyse IMMPR for non-participants or drop-outs. It remains unclear whether excess weight is an obstacle for patients and health care professionals when considering IMMPR after clinical assessment. We did not have enough information about obesity-related health problems that could have contributed to nonparticipation or drop-outs. Because the conclusions of this study are based on a population referred to tertiary care for pain rehabilitation that completed IMMPR and follow-up registrations, the generalizability of our findings are limited. Second, because we did not consider other obesity comorbidities, we may be neglecting the multi-morbidity influence on outcomes of pain rehabilitation. Our earlier research showed that certain comorbidities play an important role in older patients (Dong, Larsson, Levin, Bernfort, \& Gerdle, 2018). However, IMMPR participants in Sweden are usually of working ages and one of the main IMMPR's goals is return to work/study (Gerdle et al., 2016). Third, we paid most attention to HRQoL, one of several outcome domains in IMMPR, to analyse whether weight status affects HRQoL. Thus, the positive conclusion of benefits from IMMPR with respect to PCS and MCS regardless of excess weight cannot simply be extended to other outcomes. Future studies should explore other outcome domains of IMMPR, especially from the perspective of patients with severe obesity. 
Conclusion

We observed improved HRQoL from IMMPR applied to patients with a BMI range from normal weight to obesity. This finding suggests that rehabilitation professionals should consider using IMMPR for patients with comorbid obesity, even though their progress may not be as great as non-obese patients. This study showed that only severe obesity was negatively associated with physical health aspects of HRQoL (PCS) after IMMPR when important aspects of the clinical presentation such as pain intensity, spreading of pain, and psychological distress were considered. 


\section{Acknowledgement}

We are very grateful to Annelie Inghilesi Larsson Quality Stat AB for extracting the data from SQRP.

\section{Authors' contributions}

All authors contributed to the conception of the study. HJD analysed the data in close

collaboration with BG. HJD drafted the manuscript. All the authors commented on different

versions of the manuscript and all the authors approved the final version of the manuscript.

\section{References:}

Altman, D. G. (1991). Practical Statistics for Medical Research. London: Chapman \& Hall.

Arranz, L. I., Rafecas, M., \& Alegre, C. (2014). Effects of obesity on function and quality of life in chronic pain conditions. Curr Rheumatol Rep, 16(1), 390. doi:10.1007/s11926-013-0390-7

Barofsky, I., Fontaine, K. R., \& Cheskin, L. J. (1997). Pain in the obese: impact on health-related quality-of-life. Ann Behav Med, 19(4), 408-410. doi:10.1007/BF02895160

Bernfort, L., Gerdle, B., Rahmqvist, M., Husberg, M., \& Levin, L. A. (2015). Severity of chronic pain in an elderly population in Sweden--impact on costs and quality of life. Pain, 156(3), 521-527. doi:10.1097/01.j.pain.0000460336.31600.01

Bjelland, I., Dahl, A. A., Haug, T. T., \& Neckelmann, D. (2002). The validity of the Hospital Anxiety and Depression Scale. An updated literature review. J Psychosom Res, 52(2), 69-77. Retrieved from https://www.ncbi.nlm.nih.gov/pubmed/11832252

Borsbo, B., Peolsson, M., \& Gerdle, B. (2009). The complex interplay between pain intensity, depression, anxiety and catastrophising with respect to quality of life and disability. Disabil Rehabil, 31(19), 1605-1613. Retrieved from https://www.ncbi.nlm.nih.gov/pubmed/19848559

Boston Consulting Group. Nationell satsning på kvalitetsregister inom vården (In Swedish). (2010). Retrieved from http://www.forskasverige.se/wp-content/uploads/Nationell-SatsningKvalitetsregister.pdf

Breivik, H., Collett, B., Ventafridda, V., Cohen, R., \& Gallacher, D. (2006). Survey of chronic pain in Europe: prevalence, impact on daily life, and treatment. Eur J Pain, 10(4), 287-333. doi:10.1016/j.ejpain.2005.06.009

Bromley Milton, M., Borsbo, B., Rovner, G., Lundgren-Nilsson, A., Stibrant-Sunnerhagen, K., \& Gerdle, B. (2013). Is Pain Intensity Really That Important to Assess in Chronic Pain Patients? A Study Based on the Swedish Quality Registry for Pain Rehabilitation (SQRP). PLoS One, 8(6), e65483. doi:10.1371/journal.pone.0065483

Castel, A., Castro, S., Fontova, R., Poveda, M. J., Cascon-Pereira, R., Montull, S., . . Rull, M. (2015). Body mass index and response to a multidisciplinary treatment of fibromyalgia. Rheumatol Int, 35(2), 303-314. doi:10.1007/s00296-014-3096-x

Chopra, K., \& Arora, V. (2014). An intricate relationship between pain and depression: clinical correlates, coactivation factors and therapeutic targets. Expert Opin Ther Targets, 18(2), 159-176. doi:10.1517/14728222.2014.855720

Chu, M. C., Law, R. K., Cheung, L. C., Ma, M. L., Tse, E. Y., Wong, T. C., \& Chen, P. P. (2015). Pain management programme for Chinese patients: a 10-year outcome review. Hong Kong Med J, 21(4), 304-309. doi:10.12809/hkmj144350

Cohen, J. (1988). Statistical power analysis for the behavior sciences (2 ed.). Hillsdale, NJ: Lawrence Erlbaum Associates.

Cook, C. E. (2008). Clinimetrics Corner: The Minimal Clinically Important Change Score (MCID): A Necessary Pretense. J Man Manip Ther, 16(4), E82-83. doi:10.1179/jmt.2008.16.4.82E 
Cooper, L., Ells, L., Ryan, C., \& Martin, D. (2018). Perceptions of adults with overweight/obesity and chronic musculoskeletal pain: An interpretative phenomenological analysis. J Clin Nurs, 27(56), e776-e786. doi:10.1111/jocn.14178

Cooper, L., Ryan, C. G., Ells, L. J., Hamilton, S., Atkinson, G., Cooper, K., . . Martin, D. (2018). Weight loss interventions for adults with overweight/obesity and chronic musculoskeletal pain: a mixed methods systematic review. Obes Rev, 19(7), 989-1007. doi:10.1111/obr.12686

Dong, H. J., Larsson, B., Levin, L. A., Bernfort, L., \& Gerdle, B. (2018). Is excess weight a burden for older adults who suffer chronic pain? BMC Geriatr, 18(1), 270. doi:10.1186/s12877-0180963-4

Dunlevy, C., MacLellan, G. A., O'Malley, E., Blake, C., Breen, C., Gaynor, K., . . . O'Shea, D. (2019). Does changing weight change pain? Retrospective data analysis from a national multidisciplinary weight management service. Eur J Pain. doi:10.1002/ejp.1397

Dysvik, E., Lindstrom, T. C., Eikeland, O. J., \& Natvig, G. K. (2004). Health-related quality of life and pain beliefs among people suffering from chronic pain. Pain Manag Nurs, 5(2), 66-74. Retrieved from https://www.ncbi.nlm.nih.gov/pubmed/15297953

Farrar, J. T., Young, J. P., Jr., LaMoreaux, L., Werth, J. L., \& Poole, R. M. (2001). Clinical importance of changes in chronic pain intensity measured on an 11-point numerical pain rating scale. Pain, 94(2), 149-158. Retrieved from https://www.ncbi.nlm.nih.gov/pubmed/11690728

Gerdle, B., Molander, P., Stenberg, G., Stalnacke, B. M., \& Enthoven, P. (2016). Weak outcome predictors of multimodal rehabilitation at one-year follow-up in patients with chronic pain-a practice based evidence study from two SQRP centres. BMC Musculoskelet Disord, 17(1), 490. doi:10.1186/s12891-016-1346-7

Hallstam, A., Lofgren, M., Svensen, C., \& Stalnacke, B. M. (2016). Patients with chronic pain: Oneyear follow-up of a multimodal rehabilitation programme at a pain clinic. Scand J Pain, 10, 36-42. doi:10.1016/j.sjpain.2015.08.008

Hays, R. D., \& Morales, L. S. (2001). The RAND-36 measure of health-related quality of life. Ann Med, 33(5), 350-357. Retrieved from https://www.ncbi.nlm.nih.gov/pubmed/11491194

Hays, R. D., Sherbourne, C. D., \& Mazel, R. M. (1993). The RAND 36-Item Health Survey 1.0. Health Econ, 2(3), 217-227. Retrieved from https://www.ncbi.nlm.nih.gov/pubmed/8275167

Heo, M., Allison, D. B., Faith, M. S., Zhu, S., \& Fontaine, K. R. (2003). Obesity and quality of life: mediating effects of pain and comorbidities. Obes Res, 11(2), 209-216. doi:10.1038/oby.2003.33

Hitt, H. C., McMillen, R. C., Thornton-Neaves, T., Koch, K., \& Cosby, A. G. (2007). Comorbidity of obesity and pain in a general population: results from the Southern Pain Prevalence Study. $J$ Pain, 8(5), 430-436. doi:10.1016/j.jpain.2006.12.003

Horng, Y. S., Hwang, Y. H., Wu, H. C., Liang, H. W., Mhe, Y. J., Twu, F. C., \& Wang, J. D. (2005). Predicting health-related quality of life in patients with low back pain. Spine (Phila Pa 1976), 30(5), 551-555. Retrieved from https://www.ncbi.nlm.nih.gov/pubmed/15738789

Janke, E. A., Fritz, M., Hopkins, C., Haltzman, B., Sautter, J. M., \& Ramirez, M. L. (2014). A randomized clinical trial of an integrated behavioral self-management intervention Simultaneously Targeting Obesity and Pain: the STOP trial. BMC public health, 14, 621. doi:10.1186/14712458-14-621

Jia, H., \& Lubetkin, E. I. (2005). The impact of obesity on health-related quality-of-life in the general adult US population. J Public Health (Oxf), 27(2), 156-164. doi:10.1093/pubmed/fdi025

Kaiser, U., Kopkow, C., Deckert, S., Neustadt, K., Jacobi, L., Cameron, P., . . Schmitt, J. (2018). Developing a core outcome domain set to assessing effectiveness of interdisciplinary multimodal pain therapy: the VAPAIN consensus statement on core outcome domains. Pain, 159(4), 673-683. doi:10.1097/j.pain.0000000000001129

Koball, A. M., Craner, J., \& Sperry, J. (2016). Impact of weight status on physical and psychological outcomes of a comprehensive pain rehabilitation programme. J Rehabil Med, 48(7), 632635. doi:10.2340/16501977-2111 
Kuczmarski, M. F., Kuczmarski, R. J., \& Najjar, M. (2001). Effects of age on validity of self-reported height, weight, and body mass index: findings from the Third National Health and Nutrition Examination Survey, 1988-1994. J Am Diet Assoc, 101(1), 28-34; quiz 35-26. doi:10.1016/S0002-8223(01)00008-6

Lakens, D. (2013). Calculating and reporting effect sizes to facilitate cumulative science: a practical primer for t-tests and ANOVAs. Front Psychol, 4, 863. doi:10.3389/fpsyg.2013.00863

Lisspers, J., Nygren, A., \& Soderman, E. (1997). Hospital Anxiety and Depression Scale (HAD): some psychometric data for a Swedish sample. Acta Psychiatr Scand, 96(4), 281-286. Retrieved from https://www.ncbi.nlm.nih.gov/pubmed/9350957

Marcus, D. A. (2004). Obesity and the impact of chronic pain. Clin J Pain, 20(3), 186-191. Retrieved from https://www.ncbi.nlm.nih.gov/pubmed/15100595

Marques, A., Peralta, M., Naia, A., Loureiro, N., \& de Matos, M. G. (2018). Prevalence of adult overweight and obesity in 20 European countries, 2014. Eur J Public Health, 28(2), 295-300. doi:10.1093/eurpub/ckx143

Masheb, R. M., Lutes, L. D., Kim, H. M., Holleman, R. G., Goodrich, D. E., Janney, C. A., . . Damschroder, L. J. (2015). Weight loss outcomes in patients with pain. Obesity (Silver Spring), 23(9), 1778-1784. doi:10.1002/oby.21160

McVinnie, D. S. (2013). Obesity and pain. Br J Pain, 7(4), 163-170. doi:10.1177/2049463713484296

Molander, P., Dong, H. J., Ang, B., Enthoven, P., \& Gerdle, B. (2018). The role of pain in chronic pain patients' perception of health-related quality of life: a cross-sectional SQRP study of 40,000 patients. Scand J Pain, 18(3), 417-429. doi:10.1515/sjpain-2018-0003

Narouze, S., \& Souzdalnitski, D. (2015). Obesity and chronic pain: systematic review of prevalence and implications for pain practice. Reg Anesth Pain Med, 40(2), 91-111. doi:10.1097/AAP.0000000000000218

Nicolson, S. E., Caplan, J. P., Williams, D. E., \& Stern, T. A. (2009). Comorbid pain, depression, and anxiety: multifaceted pathology allows for multifaceted treatment. Harv Rev Psychiatry, 17(6), 407-420. doi:10.3109/10673220903463226

Norrefalk, J. R., Ekholm, K., Linder, J., Borg, K., \& Ekholm, J. (2008). Evaluation of a multiprofessional rehabilitation programme for persistent musculoskeletal-related pain: economic benefits of return to work. J Rehabil Med, 4O(1), 15-22. doi:10.2340/16501977-0131

Okifuji, A., \& Hare, B. D. (2015). The association between chronic pain and obesity. J Pain Res, 8, 399408. doi:10.2147/JPR.S55598

Phillips, C. J. (2009). The Cost and Burden of Chronic Pain. Rev Pain, 3(1), 2-5. doi:10.1177/204946370900300102

Rivano Fischer, M., Persson, E. B., Stalnacke, B. M., Schult, M. L., \& Lofgren, M. (2019). Return to work after interdisciplinary pain rehabilitation: One- and two-year follow-up based on the Swedish Quality Registry for Pain rehabilitation. J Rehabil Med, 51(4), 281-289. doi:10.2340/16501977-2544

Ryan, C. G., Vijayaraman, A., Denny, V., Ogier, A., Ells, L., Wellburn, S., . . Atkinson, G. (2017). The association between baseline persistent pain and weight change in patients attending a specialist weight management service. PLoS One, 12(6), e0179227. doi:10.1371/journal.pone.0179227

Sellinger, J. J., Clark, E. A., Shulman, M., Rosenberger, P. H., Heapy, A. A., \& Kerns, R. D. (2010). The moderating effect of obesity on cognitive-behavioral pain treatment outcomes. Pain Med, 11(9), 1381-1390. doi:10.1111/j.1526-4637.2010.00935.x

Simon, G. E., Von Korff, M., Saunders, K., Miglioretti, D. L., Crane, P. K., van Belle, G., \& Kessler, R. C. (2006). Association between obesity and psychiatric disorders in the US adult population. Arch Gen Psychiatry, 63(7), 824-830. doi:10.1001/archpsyc.63.7.824

Singer, J. D., \& Willett, J. B. (2003). Doing Data Analysis with the Multilevel Model for Change. In Applied Longitudinal Data Analysis (pp. 75-137). New York: Oxford University Press. 
Sletten, C. D., Kurklinsky, S., Chinburapa, V., \& Ghazi, S. (2015). Economic analysis of a comprehensive pain rehabilitation program: a collaboration between Florida Blue and Mayo Clinic Florida. Pain Med, 16(5), 898-904. doi:10.1111/pme.12679

Stone, A. A., \& Broderick, J. E. (2012). Obesity and pain are associated in the United States. Obesity (Silver Spring), 20(7), 1491-1495. doi:10.1038/oby.2011.397

Sweden, P. H. A. O. (2018, 2018 May 22). Overweight and obesity.

Tremmel, M., Gerdtham, U. G., Nilsson, P. M., \& Saha, S. (2017). Economic Burden of Obesity: A Systematic Literature Review. Int J Environ Res Public Health, 14(4). doi:10.3390/ijerph14040435

Turk, D. C., Dworkin, R. H., Revicki, D., Harding, G., Burke, L. B., Cella, D., ... Rappaport, B. A. (2008). Identifying important outcome domains for chronic pain clinical trials: An IMMPACT survey of people with pain. Pain, 137(2), 276-285. doi:10.1016/j.pain.2007.09.002

Turk, D. C., \& Okifuji, A. (1999). Assessment of patients' reporting of pain: an integrated perspective. Lancet, 353(9166), 1784-1788. doi:10.1016/S0140-6736(99)01309-4

Vuksanović, M., Safer, A., Palm, F., Stieglbauer, G., Grau, A., \& Becher, H. (2014). Validity of selfreported BMI in older adults and an adjustment model. Journal of Public Health, 22(3), 257263. doi:10.1007/s10389-014-0619-6

Westman, A., Linton, S. J., Theorell, T., Ohrvik, J., Wahlen, P., \& Leppert, J. (2006). Quality of life and maintenance of improvements after early multimodal rehabilitation: a 5 -year follow-up. Disabil Rehabil, 28(7), 437-446. doi:10.1080/09638280500192694

Zdziarski, L. A., Wasser, J. G., \& Vincent, H. K. (2015). Chronic pain management in the obese patient: a focused review of key challenges and potential exercise solutions. J Pain Res, 8, 63-77. doi:10.2147/JPR.S55360

Zigmond, A. S., \& Snaith, R. P. (1983). The hospital anxiety and depression scale. Acta Psychiatr Scand, 67(6), 361-370. Retrieved from https://www.ncbi.nlm.nih.gov/pubmed/6880820

\section{Legends for illustrations and tables}

Table 1. Sociodemographic characteristics of the study population.

Table 2. Comparisons among BMI categories.

Figure 1. Rand 36 Physical Component Summary (PCS).

Figure 2. Rand 36 Mental Component Summary (MCS).

Table 3. Linear mixed regression. 
Table 1. Sociodemographic characteristics of the study population.

\begin{tabular}{l|l}
\hline IMMPR participants, N=872 & n (\%) \\
\hline Age (years), mean \pm SD $^{\mathbf{a}}$ & $45.8 \pm 10.5$ \\
Female gender & $700(80.3)$ \\
Birth of place $^{\mathbf{b}}$ & $732(83.9)$ \\
$\quad$ Sweden & $46(5.3)$ \\
$\quad$ Another country in Europe & $91(10.4)$ \\
$\quad$ Outside of Europe & $244(28.0)$ \\
Highest education, college/university & \\
Current working or studying & $474(57.4)$ \\
Pre-IMMPR & $644(73.9)^{\mathrm{d}}$ \\
FU-IMMPR & \\
Body Mass index (BMI), mean \pm SD & $27.45 \pm 5.18$ \\
Pre-IMMPR & $27.33 \pm 4.99^{\mathrm{e}}$ \\
FU-IMMPR c & $12(1.4)$ \\
BMI group & $12(1.4)$ \\
Underweight & $280(32.1)$ \\
Normal weight & $356(40.8)$ \\
Overweight & $161(18.5)$ \\
Mild obese & $63(7.2)$ \\
Severely obese &
\end{tabular}

Missing data: ${ }^{\mathrm{a}}=5,{ }^{\mathrm{b}}=3, \mathrm{c}=108$;

Pre- vs. FU-IMMPR: ${ }^{\mathrm{d}}$ Chi-square, $\mathrm{P}<0.001$; ${ }^{\mathrm{e}}$ Paired t test, $P=0.599$ 
Table 2. Comparisons among BMI categories.

\begin{tabular}{|c|c|c|c|c|c|}
\hline & $\begin{array}{l}\text { Normal weight } \\
\mathbf{N}=\mathbf{2 8 0}\end{array}$ & $\begin{array}{l}\text { Overweight } \\
\mathrm{N}=356\end{array}$ & $\begin{array}{l}\text { Mild obesity } \\
\mathrm{N}=161\end{array}$ & $\begin{array}{l}\text { Severe obesity } \\
N=63\end{array}$ & P-value \\
\hline \multicolumn{6}{|l|}{ Pain aspects } \\
\hline Pain duration, days, median (q1-q3) & $1755(824-4146)$ & $1969(922-4948)$ & $\begin{array}{l}2772(914- \\
6708)^{\text {ae }}\end{array}$ & $\begin{array}{l}3752(1108- \\
7254)^{\text {be }}\end{array}$ & 0.01 \\
\hline $\begin{array}{l}\text { Pain-persistent- duration, days, median } \\
\text { (q1-q3) }\end{array}$ & $1160(511-2644)$ & $1311(616-3719)$ & $\begin{array}{l}1832(737- \\
6035)^{\mathrm{ae}}\end{array}$ & $1884(620-6502)$ & 0.008 \\
\hline PRI, Mean \pm SD & $13 \pm 8$ & $15 \pm 8$ & $17 \pm 8^{\text {ad }}$ & $17 \pm 9^{\mathrm{bc}}$ & $<0.001$ \\
\hline \multicolumn{6}{|l|}{ NRS-7d, Mean \pm SD } \\
\hline Pre-IMMPR & $6.5 \pm 1.9$ & $6.6 \pm 1.8$ & $6.9 \pm 1.7$ & $7.0 \pm 1.6$ & 0.045 \\
\hline Post-IMMPR & $5.4 \pm 2.4$ & $5.3 \pm 2.3$ & $5.7 \pm 2.1$ & $5.9 \pm 2.1$ & 0.081 \\
\hline FU-IMMPR & $5.4 \pm 2.3$ & $6.8 \pm 2.3$ & $6.2 \pm 2.3^{\mathrm{ad}}$ & $6.4 \pm 2.0^{\mathrm{bd}}$ & $<0.001$ \\
\hline $\begin{array}{l}\text { Absolute Cohen's d (Pre- vs FU- } \\
\text { IMMPR) }\end{array}$ & 0.453 & 0.332 & 0.346 & 0.328 & \\
\hline \multicolumn{6}{|l|}{ Psychological symptoms } \\
\hline \multicolumn{6}{|l|}{ HADS-A, Mean \pm SD } \\
\hline Pre-IMMPR & $9.3 \pm 4.5$ & $9.2 \pm 4.5$ & $9.1 \pm 4.5$ & $9.2 \pm 5.1$ & 0.95 \\
\hline Post-IMMPR & $7.5 \pm 4.2$ & $7.6 \pm 4.4$ & $7.6 \pm 4.4$ & $7.8 \pm 4.9$ & 0.959 \\
\hline FU- IMMPR & $7.5 \pm 4.2$ & $7.5 \pm 4.4$ & $7.6 \pm 4.7$ & $7.8 \pm 4.7$ & 0.963 \\
\hline Cohen's d (Pre- vs FU-IMMPR) & 0.444 & 0.429 & 0.385 & 0.363 & - \\
\hline
\end{tabular}




\begin{tabular}{|c|c|c|c|c|c|}
\hline \multicolumn{6}{|l|}{ HADS-D, Mean \pm SD } \\
\hline Pre-IMMPR & $8.3 \pm 4.1$ & $8.7 \pm 4.2$ & $9.3 \pm 4.2$ & $9.1 \pm 4.1$ & 0.079 \\
\hline Post-IMMPR & $6.1 \pm 4.0$ & $6.7 \pm 3.9$ & $6.8 \pm 4.1$ & $6.2 \pm 3.7$ & 0.17 \\
\hline FU-IMMPR & $6.5 \pm 4.4$ & $6.9 \pm 4.2$ & $7.0 \pm 4.7$ & $7.3 \pm 4.5$ & 0.496 \\
\hline Cohen's d (Pre- vs FU-IMMPR) & 0.430 & 0.460 & 0.524 & 0.426 & - \\
\hline
\end{tabular}

Post-hoc: ${ }^{a}$ mild obesity vs. normal weight significant, ${ }^{\mathrm{b}}$ severe obesity vs. normal weight significant; ${ }^{\mathrm{c}} \mathrm{P}<0.05$, ${ }^{\mathrm{d}} \mathrm{P}<0.01$ (ANOVA, Bonferroni method), ${ }^{\mathrm{e}} \mathrm{P}<0.017$ (Mann-Whitney U test, Bonferroni method). Cohen's d for effect size: large $(\mathrm{d} \geqslant 0.80)$, moderate $(\mathrm{d}=0.50-0.79)$, small $(d=0.20-0.49)$, and insignificant $(d<0.20)$.

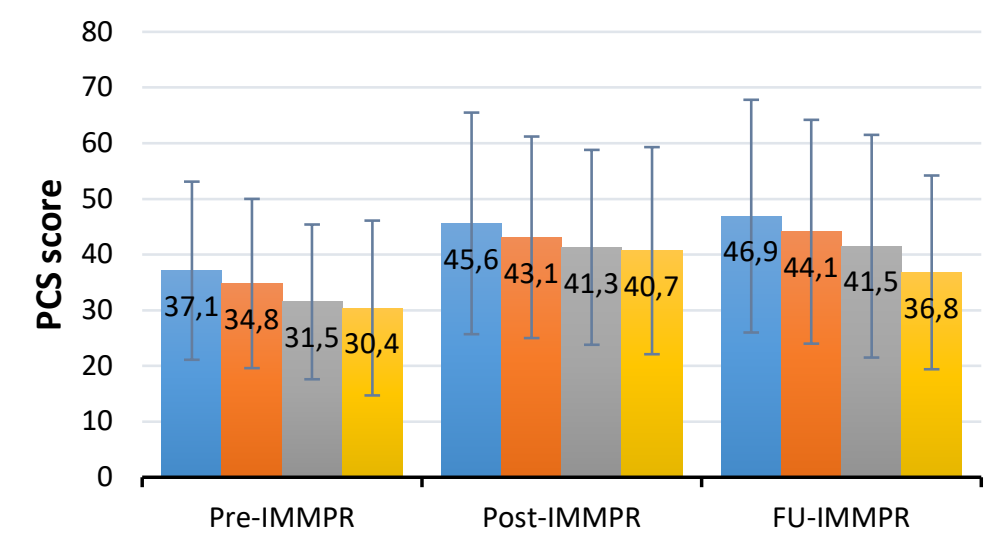

Normal weight $\square$ Overweight $\square$ Mild obesity $\square$ Severe obesity

Figure 1. Rand 36 Physical Component Summary (PCS)

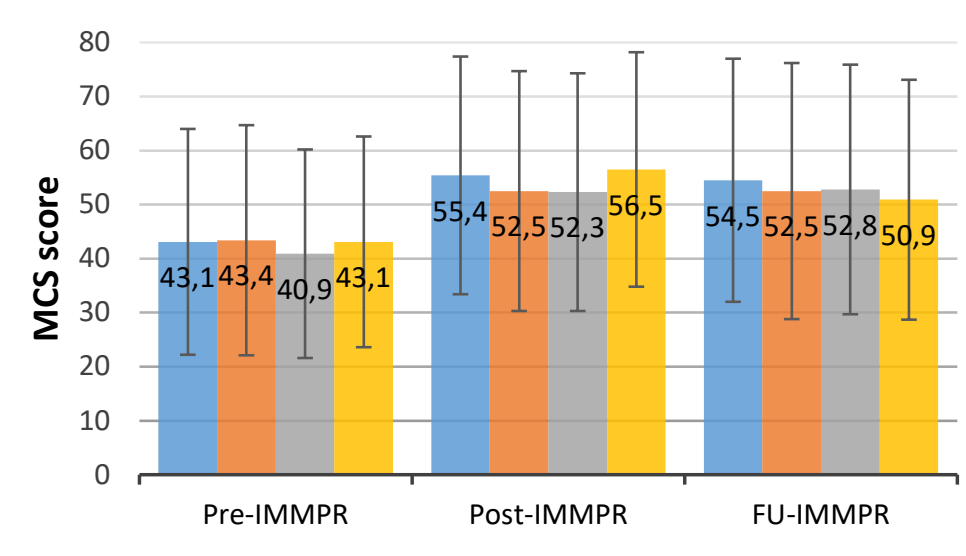

Normal weight $\square$ Overweight $\square$ Mild obesity Severe obesity

Figure 2. Rand 36 Mental Component Summary (MCS) 
Table 3. Linear mixed regression.

\begin{tabular}{|c|c|c|c|c|c|c|}
\hline \multirow{2}{*}{$\underbrace{\text { Estimate }(S E)}_{\text {Predictors }}$} & \multicolumn{3}{|c|}{ Dependent variable: PCS } & \multicolumn{3}{|c|}{ Dependent variable: MCS } \\
\hline & $\begin{array}{l}\text { Model } 1 \\
(\mathrm{n}=852)\end{array}$ & $\begin{array}{l}\text { Model } 2 \\
(\mathrm{n}=847)\end{array}$ & $\begin{array}{l}\text { Model } 3 \\
(\mathrm{n}=779)\end{array}$ & $\begin{array}{l}\text { Model } 1 \\
(\mathrm{n}=850)\end{array}$ & $\begin{array}{l}\text { Model } 2 \\
(\mathrm{n}=845)\end{array}$ & $\begin{array}{l}\text { Model } 3 \\
(\mathrm{n}=776)\end{array}$ \\
\hline $\begin{array}{l}\text { Time, reference FU- } \\
\text { IMMPR }\end{array}$ & & & & & & NS \\
\hline Pre-IMMPR & $-9.90(1.08)^{b}$ & $-9.22(1.09)^{b}$ & $-3.78(0.96)^{b}$ & $-10.85(1.44)^{b}$ & $-9.69(1.46)^{b}$ & - \\
\hline Post-IMMPR & $-1.05(1.03)$ & $-1.05(1.05)$ & $-2.36(0.97)^{\mathrm{a}}$ & $1.21(1.32)$ & $1.32(1.35)$ & - \\
\hline $\begin{array}{l}\text { BMI group, (reference } \\
\text { normal weight) }\end{array}$ & & & & NS & NS & NS \\
\hline Overweight & $-2.77(1.64)$ & $-2.31(1.63)$ & $0.26(1.19)$ & - & - & - \\
\hline Mild obesity & $-5.59(2.04)^{b}$ & $-5.43(2.00)^{\mathrm{b}}$ & $0.06(1.47)$ & - & - & - \\
\hline Severe obesity & $-10.34(2.89)^{b}$ & $-9.46(2.83)^{b}$ & $-4.39(2.10)^{\mathrm{a}}$ & - & - & - \\
\hline University/college & - & $3.24(1.11)^{b}$ & NS & - & NS & - \\
\hline Male gender & - & $3.04(1.25)^{\mathrm{a}}$ & NS & - & $4.32(1.52)^{b}$ & - \\
\hline Work/study & - & $3.36(0.71)^{b}$ & $1.80(0.63)^{b}$ & - & $5.70(0.96)^{b}$ & $1.60(0.70)^{\mathrm{a}}$ \\
\hline Born in Sweden & - & $5.07(1.38)^{\mathrm{b}}$ & NS & - & $9.62(1.70)^{b}$ & \\
\hline NRS-7d & - & - & $-3.29(0.15)^{b}$ & - & - & $-1.31(0.17)^{b}$ \\
\hline PRI & - & - & $-0.33(0.05)^{\mathrm{a}}$ & - & - & $-0.17(0.05)^{b}$ \\
\hline HADS-A & - & - & NS & - & - & $-1.44(0.11)^{b}$ \\
\hline HADS-D & - & - & $-1.20(0.09)^{b}$ & - & - & $-2.53(0.10)^{b}$ \\
\hline Change in BMI & NS & NS & NS & NS & NS & NS \\
\hline BMI x time & NS & NS & NS & NS & NS & NS \\
\hline
\end{tabular}

Model 1: BMI, time, change in BMI and BMI x time were tested; Model 2: sociodemographic variables were added; Model 3: pain aspects and psychological symptoms were added; ${ }^{\mathrm{a}} \mathrm{P}<0.05,{ }^{\mathrm{b}} \mathrm{P}<0.01$, NS: non significance. 